\title{
ARQUeOlogía HiSTÓRICA EN LAS «HUACAS» DE LA CIUDAD DE LIMA: AMPLIANDO LA NARRATIVA
}

\author{
Rosabella Álvarez-Calderón ${ }^{\mathrm{a}}$
}

\begin{abstract}
Resumen
¿Quién investiga y construye la narrativa de los sitios arqueológicos en la ciudad de Lima, conocidos localmente como huacas? Tradicionalmente, esta tarea ha sido responsabilidad de los arqueólogos profesionales, que, en la investigación, conservación y, sobre todo, en los trabajos de "puesta en valor», suelen privilegiar el periodo de construcción, uso original y transformaciones de estos sitios durante la época prehispánica, marginando e incluso haciendo invisible el papel que las huacas tuvieron durante la Colonia y la República. Esta narrativa es problemática, puesto que, de manera subjetiva, "congela» a las huacas en un periodo delimitado, y sugiere que su valor y significado se encuentra solamente en un pasado especifico. Siguiendo esta narrativa, las huacas son presentadas como espacios estáticos, en vez de espacios dinámicos que cambian con el tiempo, donde todos los periodos históricos — incluido el periodo de ruina - contribuyen de manera significativa a su estado actual. Inspirados en la estrategia de investigación, conservación y puesta en valor aplicada en Huantinamarca en el distrito de San Miguel, proponemos ampliar la narrativa de las huacas e incluir todos los periodos históricos, incluso aquella historia percibida como "negativa" para asi construir una narrativa más completa, auténtica e inclusiva.
\end{abstract}

Palabras clave: huaca, narrativa, ruina, ciclo de vida, Lima, historia negativa

\section{Abstract}

\section{HISTORICAL ARCHAEOLOGY OF THE «HUACAS» OF LIMA: EXPANDING THE NARRATIVE}

Who studies and creates the narratives that surround the city of Lima's archaeological sites, known locally as huacas? Traditionally, this has been the responsibility of professional archaeologists, who in their research and conservation efforts, as well as in their efforts to convert sites into open-air museums, tend to focus almost exclusively on the prehispanic period, when these sites were initially designed, built, used, and transformed. This approach marginalizes and even renders invisible the role these huacas had during the Colonial and Republican periods. This particular narrative is problematic, since it subjectively "freezes" sites into limited time frames, and implies that the value and significance of sitez lies solely in a very specific past. Following this narrative, huacas become static entities, instead of dynamic spaces that change over time, in which all historical periods contributed significantly to their current state. Inspired by the research, conservation, and conversion of Huaca Huantinamarca (in Lima's San Miguel district) into a public space and open-air museum, this paper proposes to go beyond the traditional narrative and include all historical periods, including those periods perceived as "despised history", in order to construct a narrative that is more comprehensive, authentic, and inclusive.

Keywords: huaca, narrative, ruin, lifecycle, Lima, negative history

${ }^{a}$ Departamento de Arquitectura, Pontificia Universidad Católica del Perú

Correo electrónico: alvarezcalderon.rv@pucp.edu.pe 


\section{Introducción}

Todo comenzó con una idea derivada de la lectura de un artículo sobre la ciudad de Roma en una revista de historia mientras estudiaba en la universidad: un monumento como el Coliseo romano ha sido ruina más tiempo de lo que fue un anfiteatro. En una visita a Roma realizada años más tarde, noté que el Coliseo narraba principalmente la historia de un gran espacio público de entretenimiento, teatralidad y sacrificio de hace miles de ańos, pero ninguno de los usos posteriores que tuvo en siglos posteriores: como cantera, santuario, vivienda, fortaleza, o talleres. No se menciona que las ruinas del Coliseo fueron inspiración de numerosos artistas y viajeros siglos después, ni cómo numerosos sismos hicieron caer parte de los muros exteriores, o cómo muchas de las piedras caídas fueron usadas para construir la Basílica de San Pedro en el Vaticano. Incluso, el actual simbolismo del Coliseo, asociado a la abolición de la pena de muerte, está relacionado con su uso original, no a las reutilizaciones y transformaciones que sufrió después. Sin embargo, en otra parte del antiguo Imperio romano, el antiguo puerto de Tárraco (la actual ciudad de Tarragona, España) muestra una imagen diferente: al centro del antiguo anfiteatro romano, se encuentran los restos de una basílica cristiana; una de las plazas principales se levanta sobre la impronta del antiguo circo de carreras; cerca de la rambla moderna se ven tanto edificios renacentistas como restos de columnas romanas. La narrativa construida de Tarragona describe y presenta una ciudad con muchos niveles; la ciudad contemporánea se levanta sobre múltiples capas históricas, culturales y naturales (Fig. 1). En la ciudad, los diferentes períodos históricos coexisten en espacios verticales y horizontales, en diferentes ritmos de uso y descomposición, y en diferentes momentos de sus ciclos de vida: edificios en construcción, edificios nuevos, edificios renovados, edificios antiguos, viejos y en ruinas; todos coexisten y comparten el mismo espacio. En la Tarragona moderna, la narrativa que percibe el visitante es la de una ciudad palimpsesto: "Las ciudades son palimpsestos, o espacios con muchas capas donde los rezagos, ruinas y restos de la ciudad antigua coexisten en el presente con los signos tempranos de una imaginaria Ciudad Futura, vistazos embrionarios de lo que se viene» (Murray, 2008: 172 citado en Dawdy 2010: 770 [traducción propia]).

En la ciudad de Lima, las huacas son las evidencias más tempranas de al menos 5000 años de ocupación, uso y desarrollo del territorio, por lo que son los principales palimpsestos de la ciudad, testigos de numerosos procesos de desarrollo del territorio, y de creación de paisajes culturales y urbanos. Sin embargo, los proyectos de investigación, conservación y puesta en valor de las huacas ubicadas en la ciudad de Lima suelen concentrar sus esfuerzos y recursos en narrar solamente la historia del período prehispánico, y se margina la historia colonial y republicana.

Limitar la narrativa de las huacas al período prehispánico es problemático por muchas razones. Primero, implica que, de manera subjetiva, se "congela» a las huacas en un período delimitado, y, de este modo, se comunica que su valor y significado se encuentra principalmente en un pasado específico, no en el presente o futuro. Siguiendo esta narrativa, las huacas son presentadas como espacios relativamente estáticos, donde se valora el diseño, construcción, uso y significado inicial, pero no necesariamente los cambios y transformaciones, especialmente aquellos ocurridos durante el período colonial (1535-1821) y republicano (1821 hasta la actualidad). De la misma manera, esta es una percepción que entiende el estado de ruina y deterioro no como una parte natural del ciclo de vida de un edificio, sino como una condición negativa que hay que enmendar. Siguiendo esta idea, los períodos colonial y republicano se convierten en una historia «negativa» de la huaca, debido a que son años asociados con los procesos de ruina, transformación, destrucción y saqueo no solo de las huacas, sino de las sociedades prehispánicas locales que las construyeron y utilizaron.

¿Cuáles serían las ventajas de ir más allá de esta narrativa limitada? Una narrativa que integre la historia desde el siglo XVI permitiría entender cómo las percepciones hacia las huacas y monumentos han cambiado a lo largo de los años; la historia de cómo las huacas han impactado y han sido impactadas por el desarrollo urbano; y la historia de cómo las huacas han sido utilizadas para elaborar discursos y políticas sobre identidades, exclusión e inclusión. En un contexto en el que la mayoría del patrimonio prehispánico de Lima se encuentra en peligro constante de ser invadido 


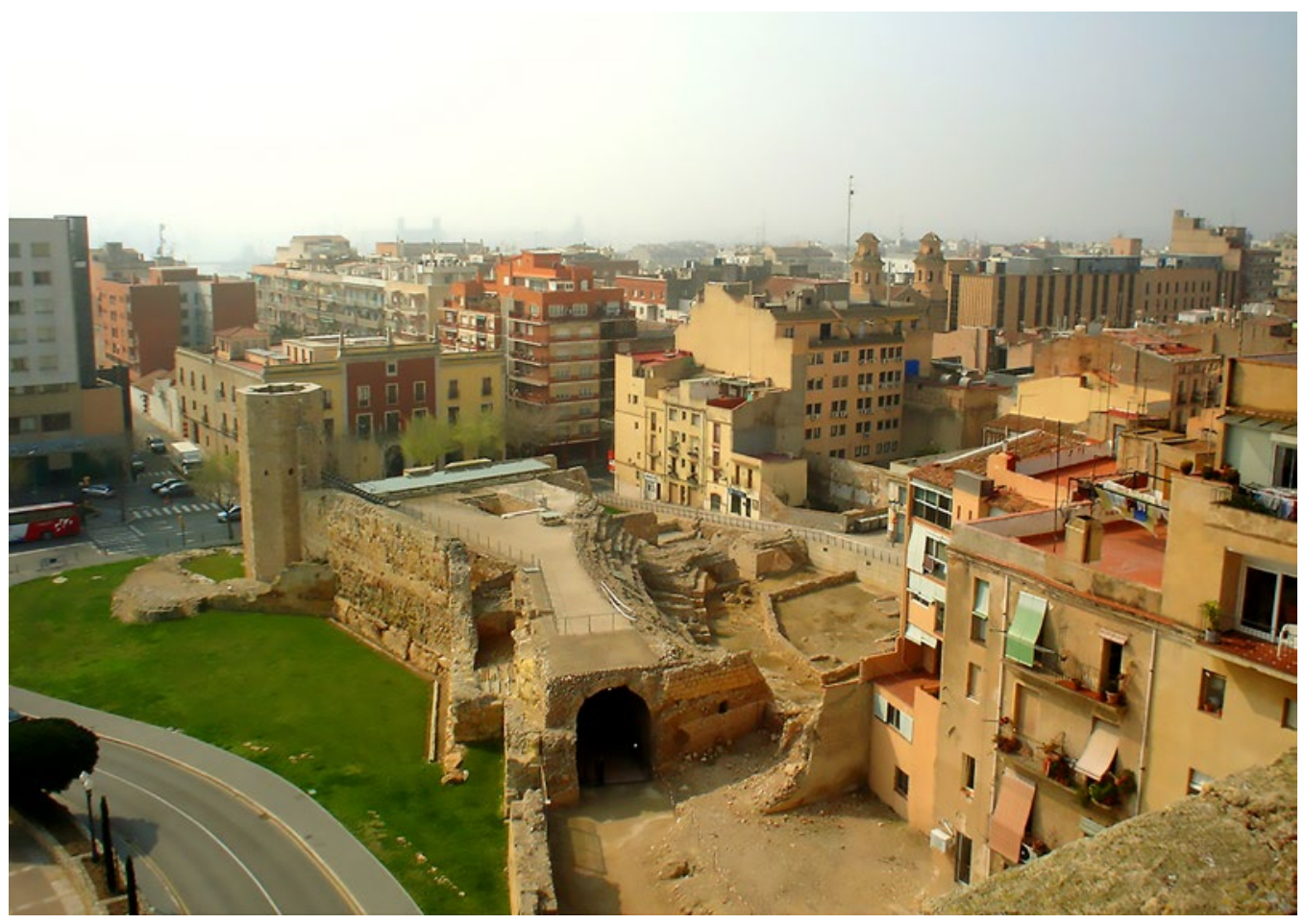

Figura 1. La ciudad de Tarragona, España, el palimpsesto urbano. Imagen de Rosabella Álvarez-Calderón SilvaSantisteban.

y destruido por las presiones de una ciudad en crecimiento, y en el que los proyectos de investigación suelen ir acompañados por intervenciones de "puesta en valor», una narrativa más completa permitiría diseñar una estrategia no solo de conservación de las huacas, sino también de integrarlas al tejido urbano y convertirlas en espacios públicos, accesibles y democráticos, aun así manteniendo su identidad e integridad como paisajes culturales históricos, como vínculos tangibles con el pasado y como materialización de la memoria colectiva.

Sin embargo, dado que las narrativas de las huacas de Lima son creadas por personas y grupos sociales, hay que considerar cuáles son los factores que contribuyen con la creación de esta narrativa limitada. Para ilustrar estos argumentos, se examinará el caso de Huantinamarca, un complejo ubicado en el distrito de San Miguel, cuyo estudio, conservación, puesta en valor e incorporación como espacio público dentro de un complejo residencial muestra una narrativa amplia que abarca desde el período prehispánico hasta la actualidad. El caso de Huantinamarca ilustra las ventajas de tener una narrativa más completa, puesto que, en este caso, cada período histórico representa una etapa en el ciclo de vida del complejo, en el que la segunda mitad del siglo XX es particularmente importante para entender por qué este sitio ha sobrevivido relativamente intacto hasta la actualidad. El caso de Huantinamarca nos muestra que, aun cuando se trate de complejos que originalmente fueron contemporáneos, cada sitio posteriormente tuvo un desarrollo individual particular en los siglos posteriores y tuvo un destino diferente cuando el área que lo rodeaba comenzó a ser urbanizada.

\section{La larga historia de las huacas}

Considerando la larga ocupación y desarrollo que tuvieron los valles donde actualmente se encuentra la ciudad de Lima (Chillón, Rímac y Lurín) antes de la llegada de los conquistadores españoles en 1535 , los edificios e infraestructura que construyeron las diferentes sociedades prehispánicas 
pasaron por numerosos ciclos de construcción, uso, ruina, destrucción, abandono, reconstrucción y renovación. No obstante, tal como se ha mencionado antes, es muy común que en la narrativa se valore y considere como patrimonio solo la parte prehispánica. Esto se podría explicar en parte por falta de conocimiento del desarrollo histórico que tuvieron las huacas a partir del período colonial y porque lo que sí se conoce - historias construidas principalmente por historiadores, urbanistas, sociólogos, arquitectos, y otros actores - no es integrado con la narrativa prehispánica, que es construida principalmente por arqueólogos profesionales. Por lo tanto, un primer paso para proponer una narrativa expandida consiste en reconocer la larga historia de las huacas, aquella historia que va más allá del período prehispánico y que incluye reconocer todos los períodos «negativos». De esta manera, la huaca deja de ser solamente un edificio congelado en un pasado específico y se convierte en un paisaje cultural histórico, que, si bien tuvo su origen y desarrollo original en el pasado, continúa siendo usado, intervenido y transformado.

Se presentará, a continuación, el caso de Huantinamarca y su larga historia, una huaca que, aunque tuvo un importante significado durante el período prehispánico tardío, también tuvo un papel fundamental en el desarrollo urbano del distrito de San Miguel a partir del siglo XX. Sin embargo, Huantinamarca también representa el caso excepcional de una huaca que, durante décadas, estuvo «escondida a simple vista», por lo que su desarrollo y actual estado de conservación responde a circunstancias muy diferentes a las de la mayoría de huacas de Lima. Conocer esta larga historia e integrarla a la narrativa de la huaca en la época prehispánica es esencial para el diseńo e implementación de estrategias sostenibles de gestión, y para la revaloración de las huacas ubicadas en la ciudad.

\section{Sacando a la luz la larga historia de Huantinamarca}

La huaca Huantinamarca, ubicada en el distrito de San Miguel, fue intervenida en el año 2009 como parte del proyecto inmobiliario Parques de la Huaca, promovido por la empresa inmobiliaria San José Perú S.A.C, a partir del cual el edificio principal fue integrado a un parque público (Figs. 2 y 3). Como parte de la intervención, se realizó un proyecto extensivo de investigación, documentación, mapeo, conservación y acondicionamiento para convertir a la huaca en un museo al aire libre, proyecto que estuvo a cargo de Arkeo Andes S.A.C, empresa especializada en investigación, gestión y difusión del patrimonio cultural. Uno de los aspectos distintivos de este proyecto es que, si bien se priorizó la documentación del edificio en la etapa prehispánica, el proyecto también abarcó el período colonial y republicano; esta larga historia fue presentada en los paneles informativos ubicados en el parque público y en la principal publicación (San José Perú S.A.C 2011), que dedica una cantidad casi equivalente de espacio tanto al período prehispánico como al desarrollo histórico durante los siglos posteriores. La publicación también documenta usos contemporáneos (la presencia de pagos y ofrendas rituales modernas), así como los más de 50 años en los que el sitio fue el escenario del auditorio al aire libre de la Feria Internacional del Pacífico ${ }^{1}$ y la Feria del Hogar.

La huaca Huantinamarca consiste principalmente en un edificio de carácter monumental ${ }^{2}$, que fue construido, remodelado y transformado en varias etapas a lo largo de muchos años. Adquirió su forma final durante el Horizonte Tardío (1476 a 1532 d.C.), durante la ocupación inca de la costa central. Huantinamarca era parte del Complejo Maranga (Middendorf 1973 [1887]), un conjunto de sitios que datan desde el período Lima, con una antigüedad de más de 1500 años, al período Inca (siglos XV a XVI); algunos de los edificios continuaron siendo utilizados durante el período colonial. El mismo sitio de Huantinamarca habría servido como asiento principal de una comunidad, y estaba integrado a la cadena productiva y ritual vinculada al acopio, transformación y consumo de chicha de maíz usada en celebraciones y rituales asociados al calendario agrícola. Al final del período prehispánico, el edificio fue convertido en mausoleo (Villacorta et al. 2011: 57-59).

Durante el período colonial (1535 a 1821), la percepción que tenían los españoles de las huacas era compleja y, a veces, contradictoria. Por un lado, expresaron admiración por la arquitectura e infraestructura construida por los incas y las sociedades que los precedieron, $y$, en muchos casos, 


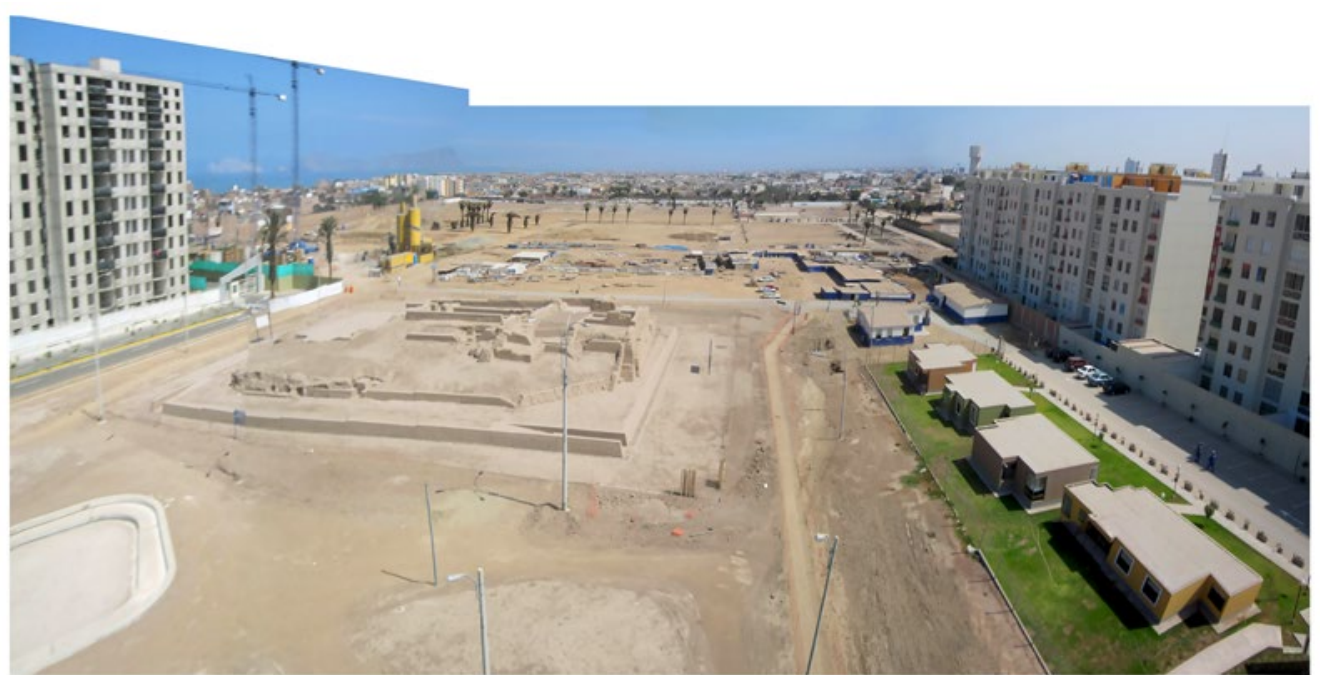

Figura 2. Vista del sitio de Huantinamarca, la residencial Parques de la Huaca, el parque (en construcción) y el distrito de San Miguel, Lima. (C) Proyecto Arqueológico Huantinamarca.

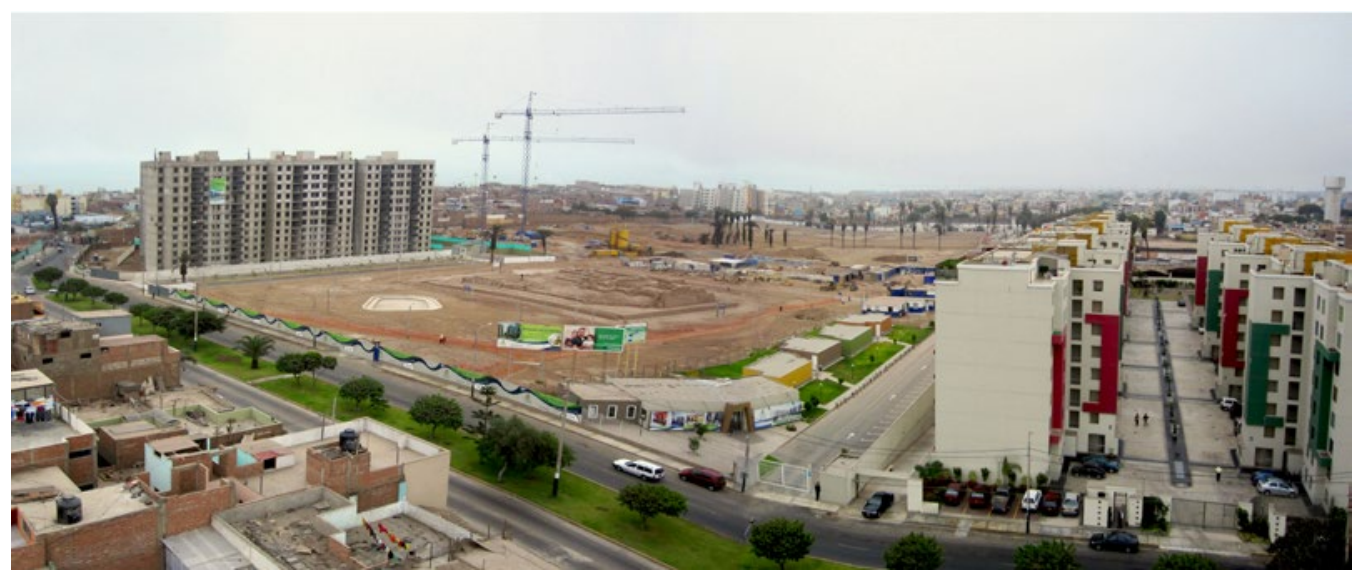

Figura 3. Vista del sitio de Huantinamarca rodeado de un parque público y de un complejo residencial (en construcción). Imagen de Erik Makera (C) Proyecto Arqueológico Huantinamarca.

continuaron utilizando los sitios para sus propios fines, frecuentemente levantando casas y otras estructuras sobre los montículos prehispánicos. Estudios arqueológicos han revelado que, durante el período colonial, varios de los sitios del Complejo Maranga, tales como la huaca Huantinamarca y la huaca Tres Palos (ubicada dentro del actual Parque de las Leyendas), fueron adaptados por los españoles para su propio uso. Se encontró restos de viviendas, establos, canales, entierros, y objetos de lujo y de uso cotidiano de estilo europeo, como cerámica vidriada, cuentas, vidrio, naipes y zapatos de cuero (Villacorta 2011b).

Sin embargo, los españoles también veían estos sitios desde su posición de conquistadores, constructores de ciudades y responsables de difundir la fe católica. El período colonial se caracterizó por saqueos intensos, explotación «minera» de huacas y la destrucción de sitios, tanto para el aprovechamiento de sus materiales de construcción como por fines simbólicos, por una gran diversidad de actores. En Huantinamarca, se encontró evidencia de que los entierros prehispánicos fueron saqueados de manera intensiva, actividad que se habría dado entre fines del siglo XVI 
e inicios del siglo XVII (Villacorta 2011b). En estos saqueos y «búsquedas de tesoros», participaron españoles, criollos e indígenas. En su texto Huacas y huaqueros de Trujillo durante el Virreinato, Jorge Zevallos Quiñones (1994) describe numerosos casos de indígenas que participaron no solo como excavadores e identificadores de huacas y "tesoros», sino también de manera más activa como denunciantes, tanto de manera individual como en asociación con españoles y criollos. Uno de estos casos, basado en el valle de Moche, consiste en un denuncio realizado en 1597 por el curaca y gobernador del pueblo de Chonche, Francisco Sicchaguamán, junto con Francisco Huamán y Pedro Pacheco, de «un entierro guaca o escondrixo questa en contorno de una legua desta ciudad poco mas o menos» (Zevallos Quiñones 1994: 57). Dado que no contaba con los fondos necesarios para realizar la excavación, Sicchaguaman se asoció con el mercader Francisco de Ayala.

Durante el período colonial, las huacas también estuvieron presentes en el imaginario y la memoria social como espacios consagrados al diablo; cabe anotar que, con «diablo», se aludía a la representación de las divinidades andinas tras la conquista española o toda aquella religión que no fuese la católica oficial, que incluía las religiones judía y musulmana, y aquellas asociadas a las comunidades africanas. Todas las prácticas, ritos y creencias no-católicos, especialmente aquellos relacionados con los sistemas de creencias y divinidades andinas prehispánicas, eran considerados idolatrías. Dentro de ese marco, las huacas se constituían como uno de sus principales escenarios, además de ser consideradas espacios para el enterramiento de gentiles (gente no bautizada en el credo cristiano) y la búsqueda de tesoros. Asimismo, las huacas estaban asociadas a la práctica de hechicerías, que, en el imaginario colonial español, representaba todo acto de magia, prácticas divinatorias, propiciatorias y de sanación - frecuentemente vinculadas con el consumo de la hoja de coca y el alcohol—, y practicadas por hombres y mujeres, tanto indígenas como criollos, españoles y personas de diferentes nacionalidades. Uno de los personajes más conocidos, asociado tanto con las huacas como con la práctica de la «idolatría», es Matheus Saladé, ermitaño francés luterano, que vivía en la zona que más adelante fue bautizada como Mateo Salado ${ }^{3}$ hacia mediados del siglo XVI; este fue acusado y condenado de herejía, y ejecutado en el primer Auto de Fe que se realizó en Lima en el año 1573. En su obra Del paganismo a la santidad, el historiador Juan Carlos Estenssoro (2003) documenta un caso de inicios del siglo XVIII (1706), en el cual el español Juan de Araujo pidió ayuda a un «indio brujo" para que una huaca "cediera su tesoro escondido", para lo cual, primero, realizó los ayunos rituales y sacrificios necesarios. En este caso, la presencia del «indio brujo» era necesaria, debido a que "para llegar al diablo es necesario recurrir a un intermediario capaz de transmitir el mensaje» (Estenssoro 2003: 403). De esta manera, se evidencian la asociación entre huacas, magia e idolatría; la participación de una variedad de actores (indígenas, criollos, espańoles) en estas prácticas; y las maneras como estas prácticas y creencias fueron adquiriendo elementos criollos y españoles. El ejemplo más notorio es la asociación entre las divinidades prehispánicas y el diablo occidental, que adquirió el nombre genérico de «supay» (Estenssoro 2003).

Las mujeres también estaban asociadas a la práctica de la "hechicería», tanto como practicantes como parte de la red de clientes. Estas mujeres eran principalmente jóvenes $(20$ a 40 años de edad en promedio), procedentes de las clases urbanas populares y mostraban una gran diversidad étnica. Entre las que ejercían la hechicería, una característica importante es que mayormente eran económicamente independientes, ya que no contaban con el apoyo económico de un hombre, lo que también implicaba que se encontraban al margen de la tutela masculina. La historiadora María Emma Mananrelli (1985) describe que estas mujeres comúnmente utilizaban una variedad de objetos provenientes de las huacas, como «idolillos» fabricados de cerámica y piedra para sus prácticas, lo que era visto por los inquisidores como un medio a través del cual el mismo demonio se hacía presente y «hablaba». De la misma manera, el uso de estos «objetos de huacas», en conjunto con el uso extendido de la coca y la mención al inca y a la colla en las invocaciones, era entendido como una práctica asociada tanto al inca como al diablo, ambos enemigos de la religión católica durante el período colonial. No obstante, si bien Mannarelli señala que las mujeres utilizaban estos objetos, no se hace mención a la manera como estos objetos eran adquiridos, por ejemplo, si las mismas mujeres hechiceras también se dedicaban a la «búsqueda de tesoros» en las huacas para 
obtener estos objetos o si los obtenían por terceros, principalmente, hombres. Las actividades de hechicería practicadas por mujeres eran percibidas como peligrosas por las autoridades masculinas y los inquisidores, puesto que estas mujeres «eran capaces de controlar a los hombres y atraerlos según su voluntad más allá del propio consentimiento de estos» (Mannarelli 1985: 150). De la misma manera, estas hechicerías femeninas son evidencia tanto de la posición de subordinación de las mujeres durante la Colonia, así como de una resistencia a la imposición de roles de género tradicionales, y un esfuerzo por parte de ellas cambiar o controlar sus destinos (Mannarelli 1985).

Las investigaciones arqueológicas en la huaca Huantinamarca han revelado evidencia de ofrendas propiciatorias modernas (siglos XIX y XX), una práctica que tiene raíces profundas, y está fuertemente asociada con rituales chamanísticos y magia. Los sitios arqueológicos suelen ser usados como escenarios para estas prácticas debido a la creencia de que aún hay magia, poder y sacralidad asociados a ellos (Villacorta 2011b: 176) ${ }^{4}$.

Hasta mediados del siglo XX, el área de San Miguel seguía siendo mayormente rural y compuesta de haciendas agroindustriales, así como del balneario, convertido en distrito en 1920 . Debido a este escaso desarrollo urbano, en fotografías aéreas de la época, es posible ver la densidad de sitios arqueológicos y la manera como estos se relacionaban entre sí, además de la infraestructura de apoyo, como los canales y caminos (Fig. 4). A partir de la década de 1940, tanto individuos como instituciones públicas y privadas comenzaron a adquirir grandes parcelas de tierra para su desarrollo residencial, comercial e institucional, notablemente el campo ferial al aire libre de la Feria Internacional del Pacífico, que, posteriormente, también fue sede de la Feria del Hogar. Este desarrollo de Huantinamarca se debió en gran parte a la visión del empresario suizo Gosta Lettersten, dueño y fundador de la Feria Internacional del Pacífico, de usar la huaca como un escenario para representaciones, de manera similar al uso que se les daba a los sitios arqueológicos romanos, notablemente los baños de Caracalla en la ciudad de Roma, para la representación de óperas y conciertos (Lettersten 2014; Villacorta 2013, comunicación personal). Este proceso de integración de huacas dentro de terrenos existentes, mayormente privados, significó que, durante las décadas decisivas en las cuales se urbanizó los terrenos rurales de San Miguel, años en los que muchos sitios arqueológicos fueron alterados e incluso destruidos, la huaca Huantinamarca estuvo fuera del ojo público, protegida por su ubicación en el campo ferial (Villacorta 2011b). Cuando el terreno de la Feria Internacional del Pacífico fue vendido para ser transformado en residencias y comercios a principios del siglo XXI, la percepción y discursos alrededor de los sitios arqueológicos ya habían cambiado de manera importante, y simplemente demoler la huaca ya no era una opción legal, política y socialmente válida.

La larga historia de Huantinamarca revela la historia de un edificio que, a lo largo de los ańos, fue parte del Complejo Maranga, mausoleo prehispánico, residencia de españoles, ruina dotada de poder mágico y sagrado, cementerio republicano para aquellos que no podían enterrarse en cementerios convencionales, ruina prehispánica en el paisaje rural de las haciendas, auditorio de un campo ferial y — hoy en día - es el monumento central de un parque público asociado a un complejo residencial moderno. A pesar de su valor principal como edificio de la época prehispánica, podemos ver que, a lo largo de los siglos, Huantinamarca ha acumulado un gran número de usos, percepciones, memorias y significados. Sin embargo, a diferencia de la mayoría de huacas ubicadas en la ciudad de Lima, al estar "escondida a simple vista» por su ubicación dentro de la Feria del Pacífico, Huantinamarca no llegó a ser percibida como un elemento negativo en el paisaje que obstaculizaba el proceso de urbanización del distrito; tampoco, fue usado de basural o como espacio para depositar desmonte, como sí ocurrió con huacas como Pucllana y Huallamarca. Este desarrollo diferente durante el siglo XX significa que el proceso de intervención, investigación y transformación en un parque y museo al aire libre comenzó de manera muy diferente. La conclusión que se puede obtener es que, aunque la etapa de investigación y conservación en huacas prehispánicas puede ser similar, en el proceso de "puesta en valor", y en la estrategia utilizada para integrar la huaca con la ciudad y el vecindario, tendría que tener mucho más peso el desarrollo que tuvo la huaca durante el siglo XX y, sobre todo, cómo la huaca impactó y fue impactada por el proceso de urbanización. 


\section{Una larga historia dividida}

Una de las grandes limitaciones para poder realizar un estudio más completo de esta larga historia de las huacas se debe, en parte, a las diferencias y separaciones entre las disciplinas que estudian el pasado (la arqueología, la historia, la arquitectura, la geografía, el urbanismo, entre otras), y el impacto de esta separación en las instituciones y legislación relevante. En el Perú, esta separación entre la arqueología y la historia se puede observar, por ejemplo, en el Reglamento de Investigaciones Arqueológicas del año 2000 (Instituto Nacional de Cultura 2000), en el que se distingue entre «monumentos arqueológicos prehispánicos» $\mathrm{y}$ «monumentos históricos coloniales y republicanos». De la misma manera, pese a que más adelante se menciona que las «investigaciones arqueológicas» pueden ser realizadas en sitios de origen prehispánico o histórico — que es lo que permite el desarrollo de la arqueología histórica en el Perú en primer lugar-, los artículos 2, 3 y 4 del reglamento asocian lo arqueológico exclusivamente con el período prehispánico. Más aún, estos mismos artículos especifican que los únicos sitios que son Patrimonio Cultural de la Nación, propiedad del Estado e intangibles, sin tener que ser declarados como tales, ni con necesidad de justificar su importancia, significado y valor, son aquellos sitios de origen prehispánico, sean monumentos, conjuntos, sitios aislados o paisajes culturales.

El problema con las asociaciones arqueología-estudio del período prehispánico e historiaestudio del período colonial y republicano es que crean una división artificial entre el período prehispánico e histórico, en la que lo prehispánico es considerado digno de conservarse solo por su edad, mientras que lo histórico debe justificar su valor. De la misma manera, también «congela» a las huacas y a los paisajes culturales prehispánicos en un pasado específico negando su larga historia y su naturaleza dinámica. El requisito de la intangibilidad es especialmente problemático para el caso de sitios y paisajes culturales que no solo tuvieron un importante desarrollo en tiempos históricos, sino que incluso continúan siendo utilizados hasta el día de hoy.

Una segunda limitación que restringe la narrativa oficial de la mayoría de las huacas al período prehispánico es la escasez de enfoques y estudios que trasciendan los límites tradicionales de las disciplinas, y que sean verdaderamente interdisciplinarios, así como las limitaciones que enfrentan los arqueólogos profesionales en su papel como principales investigadores, gestores y protectores de los sitios arqueológicos. En el Perú, la legislación vigente indica que las intervenciones arqueológicas (el estudio de los restos materiales, y su contexto cultural y ambiental de las sociedades del pasado), sean proyectos de evaluación, investigación, de conservación, consolidación, mantenimiento y puesta en valor, tienen que estar dirigidos por un arqueólogo profesional, aun cuando se trate de proyectos multidisciplinarios (Ministerio de Cultura 2014: artículo 13). En el Perú, los arqueólogos profesionales suelen ser los principales administradores, protectores, curadores e investigadores del patrimonio prehispánico del país, y esta profesión está regulada por principios, leyes y regulaciones locales e internacionales ${ }^{5}$. Debido a su entrenamiento, habilidades y experiencia, los arqueólogos profesionales suelen ser los principales responsables del desarrollo de técnicas, métodos y estrategias para la conservación a largo plazo de las huacas, así como en la construcción de su narrativa principal, que es necesario cuando se hacen trabajos de conservación y revaloración.

Esta responsabilidad de los arqueólogos tiene su origen en los esfuerzos e investigaciones realizados por arqueólogos profesionales y aficionados desde hace casi 100 años para proteger las huacas de Lima, especialmente durante las décadas de expansión de la ciudad, y urbanización de las áreas rurales y las antiguas haciendas. A partir de la década de 1930, el arqueólogo Julio C. Tello se convirtió en un importante activista a favor de la protección de los sitios arqueológicos en la ciudad de Lima; buscaba el cumplimiento de las leyes existentes para su protección, y usaba estas leyes y su considerable prestigio y experiencia como arqueólogo para legitimar y validar su agenda, que con frecuencia lo enfrentaba con hacendados y dueños de terrenos privados (Tello 1999; Burger 2009). En las décadas siguientes, Arturo Jiménez Borja buscó la protección de huacas como Huallamarca, ubicada en el distrito de San Isidro, y Puruchuco, ubicada en el distrito de Ate, mediante la transformación de las huacas en museos al aire libre, espacios públicos abiertos, espacios educativos 


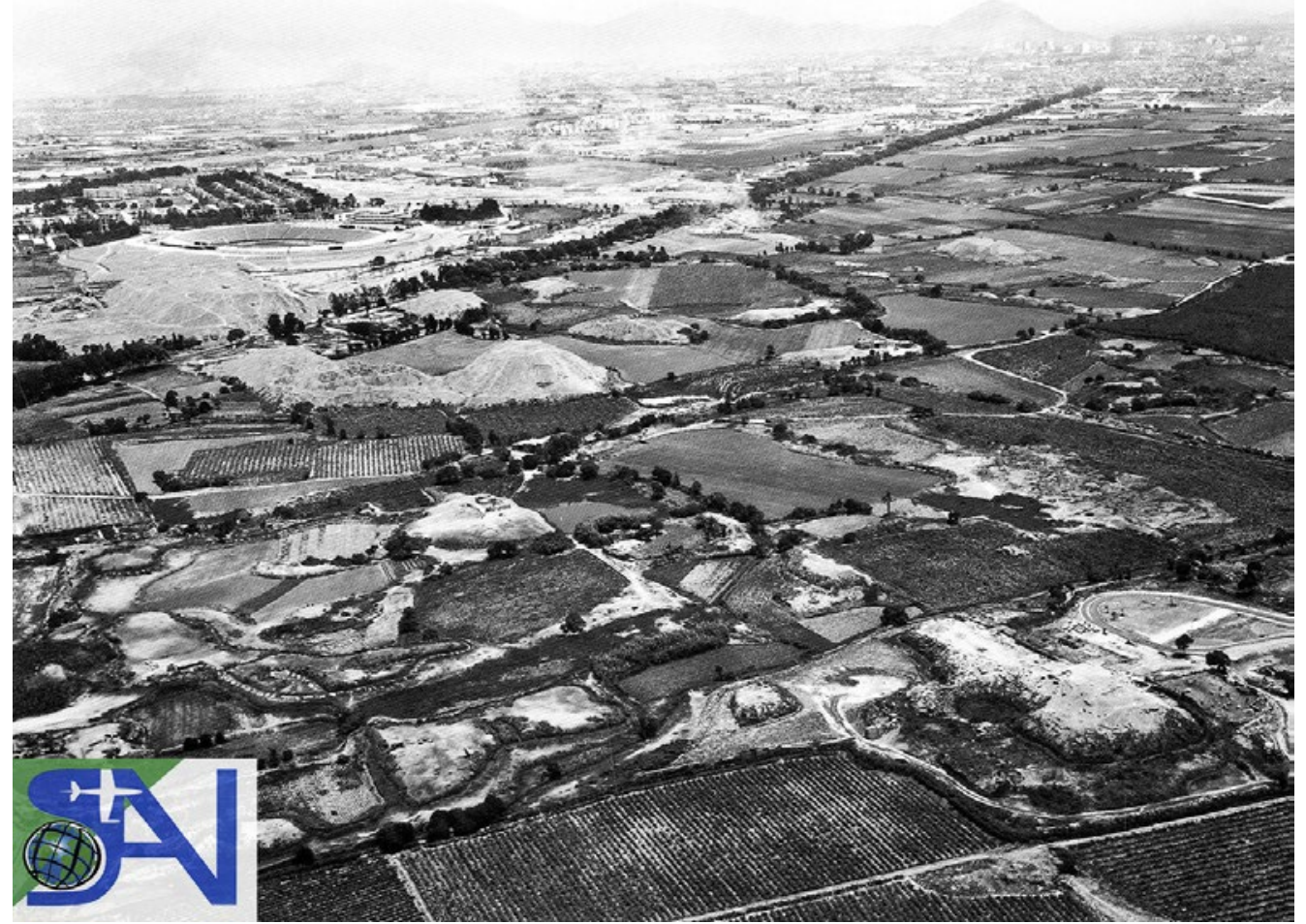

Figura 4. El paisaje rural de San Miguel, Lima, antes de su desarrollo urbano a mediados del siglo XX, mostrando el complejo de Maranga. (C) Servicio Aerofotográfico Nacional de la Fuerza Aérea del Perú

y en hitos urbanos (Villacorta 2004: 76). Esta transformación de Huallamarca fue parte de una estrategia a largo plazo que también incluía la creación de un museo de sitio, un programa de investigación arqueológica y la creación de un ambiente de "parque arqueológico». La arqueóloga Isabel Flores y su equipo realizaron una estrategia similar muchas décadas después en la huaca Pucllana, que también estaba en riesgo de ser destruida (Flores 2002). En todos estos casos, los arqueólogos crearon una narrativa asociada, a través del museo de sitio, publicaciones y carteles informativos. De la misma manera, un paso importante para poder convertir a las huacas en paisajes culturales fue asociarlos con la historia y la formación de la identidad nacional.

A pesar de la labor importante que realizan los arqueólogos profesionales en la investigación, protección y construcción de la narrativa asociada a los sitios prehispánicos, la especialización también ha creado limitaciones no solo para estudiar el desarrollo de las huacas después de 1535, sino también para incluir las percepciones de otros actores y disciplinas a la narrativa «oficial»? La primera de estas limitaciones es la poca familiaridad y conocimiento que suelen tener los arqueólogos de los métodos y teorías de otras disciplinas, con excepción de aquellas que impactan de manera directa el trabajo arqueológico, como la geografía. La arqueología histórica cuestiona esta división tradicional entre las disciplinas al ser interdisciplinaria y colaborativa, y requiere que el investigador maneje teorías, técnicas y métodos de disciplinas muy diversas (historia, paleografía, etnografía, entre otras), y que supere las categorías cronológicas estrictas que tradicionalmente han limitado la arqueología al estudio del pasado prehispánico. Finalmente, la arqueología histórica permite combinar las metodologías, teorías y prácticas de varias disciplinas para crear un enfoque innovador. La arqueología histórica y su enfoque en la cultura material han permitido, por ejemplo, estudiar temas y actores que tradicionalmente no están cubiertos por las fuentes escritas. 
Una tercera limitación es la escasez de estudios interdisciplinarios, la ausencia de proyectos con una visión que obligue a profesionales de diferentes disciplinas a transgredir los límites impuestos por sus disciplinas particulares, y superar el celo y competencia profesional para solucionar un problema o lograr un objetivo común. Sin embargo, la aprobación del Reglamento para la Declaratoria y Gestión de los Paisajes Culturales como Patrimonio Cultural de la Nación en año $2011^{8}$ podría servir como incentivo para la realización de más proyectos interdisciplinarios, sobre la base de la descripción que se da de los paisajes culturales como «el producto de la relación continua entre el hombre y su espacio a través del tiempo» (Ministerio de Cultura 2011: artículo 6), puesto que se sugiere que se debe buscar entender la historia completa de los paisajes culturales; cómo han sido transformados, usados y valorados a través del tiempo; y no buscar «congelarlos» en un período específico. Sin embargo, este entendimiento no se puede lograr dependiendo solamente de una disciplina, sino que es un reto que requiere la colaboración y trabajo conjunto de muchas disciplinas diferentes. La ventaja de lo interdisciplinario, principalmente, es que permite constantemente ver lo existente con nuevos ojos, nuevas perspectivas.

La intervención en Huantinamarca es un ejemplo de un proyecto interdisciplinario; se trató de una colaboración entre profesionales de varias disciplinas con varios objetivos en común - la construcción de una narrativa que contara la larga historia de la huaca desde el período prehispánico hasta la actualidad-; la conservación, estabilización y «puesta en valor» del edificio; y la transformación del espacio en un paisaje cultural y en un espacio público. Estudiar la larga historia de Huantinamarca, especialmente el desarrollo del edificio durante el siglo XX, permitió formular una estrategia de gestión y valorización (no solo apreciar el valor existente, sino agregar valor) que fuese adecuada al nuevo contexto urbano del sitio, una estrategia que, si bien funcionó en el contexto de Huantinamarca y San Miguel, probablemente no sería la más adecuada para otras huacas, incluso aquellas cercanas y que datan del mismo período, como Mateo Salado, o las huacas ubicadas en el Parque de las Leyendas. Esto responde a que las huacas son percibidas y valoradas de diferentes maneras (económica, política, cultural, histórico, estética, espiritual, entre otras), y estas diferentes maneras de valorar los sitios llevan a diferentes enfoques de intervención y conservación. Por ejemplo, en un sitio en que tienen más prioridad el valor histórico-cultural y la relación con la comunidad, se dará mayor importancia al aspecto educativo, y a hacer el sitio accesible y significativo para el público. Cada estrategia de intervención y conservación responde a diferentes valores, intereses y motivaciones de los actores interesados (Avrami et al. 2000: 7-8).

\section{Repensando el concepto de «ruina» y la «historia negativa» de las huacas}

El sesgo que ha motivado a muchos arqueólogos a construir una narrativa limitada al período prehispánico también podría deberse a una visión negativa de los períodos colonial y republicano, y al hecho de que estos han sido asociados a los conceptos de deterioro y ruina en general. Investigadores como Andrew Herscher y Lynn Meskell describen los elementos materiales de esta historia negativa como «antipatrimonio» (counter-heritage) o herencia negativa, un patrimonio que es inadmisible o no reconocido por el poder hegemónico, y excluido de la narrativa «oficial» de lo que constituye la historia y el patrimonio. Sin embargo, el antipatrimonio y lo que se designa como historia negativa también sirven como marcadores de identidad: lo que uno elige destruir o excluir indica la manera como uno identifica al «otro» (Herscher 2006; Meskell 2002). En el caso de las huacas de Lima, esta exclusión de la historia colonial y republicana podría representar un esfuerzo por eliminar no solo los elementos arquitectónicos y de infraestructura asociados al proceso de ruina, deterioro y destrucción, sino también las memorias y significados asociados. De la misma manera, se trataría de una forma de estabilizar las huacas y mantenerlas en el pasado prehispánico como edificios en uso activo, a partir de la conservación de su integridad física y del divorcio de su actual contexto urbano moderno.

¿Por qué los procesos de ruina y deterioro en las huacas de Lima suelen ser vistos de manera negativa, y por qué se buscaría invisibilizar esta historia asociada a la ruina y a la destrucción? En su obra Wasting Away, Kevin Lynch (1990) plantea que los procesos de ruina y deterioro son 
percibidos como negativos, puesto que están asociados al abandono y al caos, y la gente generalmente prefiere el orden, la estabilidad y los límites definidos. De la misma manera, argumenta que el vandalismo y la destrucción ocurren con mayor frecuencia en espacios donde no hay una persona responsable claramente identificable, y donde hay señales claras de escasa supervisión, deterioro y daños que no son reparados (Lynch 1990). En el caso de las huacas de Lima, la ruina y el abandono también son percibidos como aspectos negativos, debido a que las huacas no intervenidas frecuentemente son lugares peligrosos e insalubres, en los que se arrojan basura y materiales de construcción desechados. Sin embargo, aceptar e incorporar el estado de ruina como una parte de la «larga historia» significaría aceptar la inevitabilidad del proceso de deterioro y destrucción. Significa aceptar que «ninguna creación humana dura para siempre, que el deterioro de sitios y ciudades, objetos y obras de arte, solo puede ser retardado, nunca prevenido. La descomposición química, la desintegración física, el medio ambiente cambiante, la conciencia y la percepción, y la importación simbólica alteran todo el patrimonio de manera imparable» (Lowenthal 2002: 20 [traducción propia]).

Una posibilidad es que excluir el estado de ruina de la historia larga haya sido una estrategia para presentar a las huacas principalmente como edificios y centros de actividad del pasado, como patrimonio histórico, aunque eso signifique anular varios siglos de historia y usos posteriores. Para aquellos que abogan por la conservación y protección de las huacas, esta es una estrategia que tiene sentido en un contexto de rápida urbanización donde las huacas tienen que "ganarse» el derecho a seguir existiendo en la ciudad (un contexto que comenzó en Lima en el siglo XX y persiste hasta el día de hoy), un contexto en el que muchas huacas que eran percibidas como «ruinas» y obstáculos al desarrollo fueron demolidas, tal como ocurrió con muchas de las huacas del distrito de San Isidro (Ludeña 2003).

La historia de la huaca Pucllana durante el siglo XX ilustra lo que ocurre cuando un sitio es percibido como una ruina y abandonado: incrementa el riesgo que el sitio sea destruido, tanto lo material como las memorias y significados asociados. Durante gran parte del siglo XX, la huaca Pucllana fue severamente afectada por hacendados, promotores urbanos e inmobiliarios, e incluso la misma Municipalidad de Miraflores, que buscaba urbanizar los terrenos donde se ubicaba la huaca para incentivar el desarrollo poblacional y económico del distrito 9 (Tello 1999; Concejo Distrital de Miraflores 1952a, 1952b, 1955; Flores 2002). La defensa a favor de la protección y conservación de Pucllana fue realizada por políticos, vecinos y —especialmente- por el arqueólogo Julio C. Tello (Flores 2002). Tello respondió a las afirmaciones de hacendados, urbanizadores y de la misma Municipalidad de Miraflores que argumentaban que el sitio carecía de valor histórico y que era una «ruina» (Concejo Distrital de Miraflores 1952a, 1952b, 1955) por medio de sus investigaciones y apelando a la ley 6634, una ley de 1929 que declaraba al Estado peruano como propietario de todos los sitios arqueológicos e históricos en el territorio nacional, y también penalizaba la destrucción y las excavaciones no autorizadas en las huacas. Tello basó su defensa de Pucllana y otras huacas en su experiencia como arqueólogo, lo que le daba una percepción diferente y educada de estos sitios. En otras palabras, mientras que los hacendados y urbanizadores solo veían un cerro polvoriento cuyo principal valor era el terreno, los «tesoros» que albergaba y los materiales de construcción que podían ser extraídos (principalmente adobes), Tello veía los restos de un edificio, de actividad humana y la materialización de energía humana (Tello 1999: 69-72).

La transformación de Pucllana revela que los procesos de ruina y deterioro no son condiciones objetivas necesariamente negativas, ni describen una condición estática y definitiva. Una "ruina» puede ser simplemente un edificio o un paisaje en un proceso continuo de deterioro, que está recibiendo un uso diferente a la función original para la que fue diseñado y construido. De la misma manera, el deterioro no es estático ni sostenible, sino un proceso continuo que puede ser desacelerado o incluso temporalmente revertido, pero nunca detenido.

Según Lynch, el deterioro y la ruina pueden servir para apreciar el valor histórico y como evidencia de antigüedad, el llamado valor de la edad (age value) (Lynch 1990; Yablon 2009). Visto de esta manera, el deterioro y la erosión son representados como una pátina que sirve para legitimar 
la edad, una larga historia y para verificar la autenticidad (McCracken 1988). Esta combinación de valor histórico y valor de la edad, legitimados por el mismo proceso de ruina, significa que las huacas se convierten en el principal vínculo entre el pasado y el presente en la ciudad. El reto para los arqueólogos actuales sería determinar cómo incorporar y aceptar los procesos de ruina y deterioro ocurridos desde el siglo XVI en la narrativa oficial de las huacas, y, al mismo tiempo, cambiar la percepción de las huacas no intervenidas como espacios abandonados, que más parecen cerros naturales que edificios construidos por sociedades antiguas ${ }^{10}$.

Huantinamarca es un caso innovador de una estrategia de conservación que buscó estabilizar la estructura del edificio, y, al mismo tiempo, reconocer y visibilizar el proceso de deterioro como parte de un ciclo de vida natural. Este enfoque fue incluido en la narrativa creada para el sitio, y se puede ver en el edificio en sí, en los paneles educativos y en la publicación que documenta el trabajo realizado por el equipo de investigación y conservación. Al describir en detalle el trabajo realizado en la huaca, la narrativa evidencia que la actual apariencia de Huantinamarca es el resultado de un esfuerzo deliberado para estabilizar el proceso de deterioro con el fin de prolongar la vida del edificio, mejorar su atractivo estético y mejorar la legibilidad del sitio para los visitantes —en otras palabras, que el sitio parezca un edificio y no un cerro natural— (de las Casas y Faustino 2011).

\section{Las huacas de Lima: ¿patrimonio de quién?}

Hemos visto que una de las razones para explicar la narrativa limitada sobre las huacas de Lima se debería a una percepción negativa de historia colonial y republicana, como períodos asociados al saqueo, ruina y destrucción de las huacas. Sin embargo, hemos mencionado que la condición de ruina no tiene por qué ser una condición negativa, debido a que el deterioro puede ser usado para verificar la antigüedad del sitio y presentarlo no como un edificio congelado en el tiempo, sino como un espacio dinámico, con muchas memorias, significados y valores asociados.

Sin embargo, otra posibilidad es que la razón por la que los períodos colonial y republicano, y cómo estos se manifiestan en las huacas de la ciudad, son vistos de manera negativa sea más política y esté relacionada con temas de identidad, ciudadanía, inclusión y exclusión, y el derecho a la ciudad. Siguiendo esta idea y las propuestas de Herscher y Meskell sobre antipatrimonio y la percepción del «otro», postulamos que la narrativa limitada de las huacas y la marginalización de la larga historia representaría un acto de apropiación simbólica de las huacas como espacios del periodo prehispánico, y la creación de un patrimonio cultural asociado a un pasado prehispánico generalizado e idealizado (Lowenthal 2002). En un nivel, el acto de eliminación de esta «historia negativa» representaría una manera de excluir a ciertos actores y eventos «indeseables», como los españoles (período colonial) y los hacendados y urbanizadores (siglo XX) (Herscher 2006; Meskell 2002).

Esta narrativa limitada también sirve para fijar a las huacas como patrimonio exclusivamente prehispánico, más asociado a las poblaciones indígenas y mestizas que a la población limeña descendiente de europeos. La ironía, sin embargo, es que a veces existe en la actualidad poca relación real (geográfica, étnica o de parentesco) entre las sociedades e individuos que construyeron y utilizaron las huacas en el pasado, y sus descendientes, la mayoría de los cuales se identifican como mestizos, indígenas, migrantes y descendientes de migrantes, y habitantes tanto de "pueblos jóvenes» como de antiguas barriadas hoy en día consolidadas en distritos y barrios formales. Siglos de mestizaje, sincretismo e intercambios culturales han llevado a que incluso entre aquellos que se identifican como indígenas y «cholos» sea raro encontrar personas sin ningún ancestro europeo o internacional, especialmente, español. Esto se debe a que, durante la Colonia y la República, las diferencias étnicas entre las poblaciones peruanas locales fueron deliberadamente diluidas, al menos, en el plano legal: todas las personas indígenas se convirtieron en indios, y tenían que encajar en una de las numerosas categorías raciales creadas e impuestas por el régimen colonial español (Flores Galindo 1988). En este caso, la etiqueta de indios, así como la implicancia que tiene el hecho de que los indios eran no solo la única población nativa, sino también los antiguos habitantes del Perú, ha sido apropiada por los pobladores de muchos pueblos jóvenes, especialmente aquellos que fueron creados mediante 
el acto de invasión para obtener un beneficio y para establecer un vínculo con un pasado idealizado, que, a su vez, podía ser utilizado como patrimonio y para legitimar sus reclamos sobre la tierra (Skar 1994). La estrategia de apelar a un pasado idealizado, que no habría sido efectiva si las distinciones entre grupos étnicos hubiesen sido mantenidas y realzadas, ha sido descrita en detalle por David Lowenthal (2002) en su artículo «The past as a theme park» [ $\mathrm{El}$ pasado como parque temático»].

Marcar las huacas como patrimonio prehispánico, invisibilizar la historia colonial y republicana con su legado de ruina y destrucción, y enfatizar que este patrimonio prehispánico fue obra de los ancestros de esta población tradicionalmente marginada - los indios, los cholos, los mestizos, los andinos, provincianos, migrantes y sus descendientes, los habitantes de los pueblos jóvenes y de los ex pueblos jóvenes ahora consolidados en distritos y barrios formales - pueden ser interpretados como una estrategia, deliberada o inconsciente, de apropiación/recuperación simbólica de la ciudad, una afirmación del derecho a la ciudad, así como un esfuerzo de ampliar el concepto de lo que significa ser limeño para incluir a los migrantes y sus descendientes. Si entendemos a las huacas como la representación de un proceso de fusión cultural — la integración de diversas identidades, momentos históricos, usos, percepciones, valores y significados, aunque es posible identificar cada uno de los elementos constituyentes)—, presentar las como «sitios prehispánicos» representaría una búsqueda de la "purificación» de estos sitios, de la eliminación de elementos foráneos e «invasores» (Cohen 2000). La interpretación de las huacas como espacios prehispánicos ha sido utilizada para construir un sentido de identidad, memoria histórica, ciudadanía y construcción de la ciudad entre comunidades de migrantes y sus descendientes, como se puede ver en los trabajos de grupos como el Colectivo Colli ${ }^{11}$. De la misma manera, la campaña Lima Milenaria ${ }^{12}$ fue desarrollada con el objetivo de crear conciencia y conocimiento sobre el patrimonio arqueológico de Lima, y para crear una identidad que vinculaba a la ciudad de Lima histórica y moderna con todas las huacas y su infraestructura de apoyo.

No obstante, la existencia de grupos de activistas como Salvemos las Huacas ${ }^{13}$ y el Círculo de Ciclistas Protector de las Huacas ${ }^{14}$, así como las constantes noticias sobre la destrucción e invasión de estos sitios aun en la actualidad — como fue el caso que recibió una gran atención de la prensa: la destrucción de una de las pirámides del complejo El Paraíso en el año 2013, una acción realizada de manera ilegal con el fin de «liberar» espacio para su lotización y desarrollo inmobiliarioindican que estos sitios siguen en riesgo, a pesar de los esfuerzos y acciones para su protección; estas amenazas proceden de muchos tipos de actores sociales urbanos (individuos, comunidades, instituciones). El proceso de consolidación y formalización de los antiguos pueblos jóvenes y su transformación en distritos de la ciudad de Lima a partir de la segunda mitad del siglo XX han llevado a un incremento en el valor de la tierra, un proceso en el cual las huacas corren el riesgo de ser demolidas por el espacio que ocupan para que este pueda ser utilizado para viviendas, comercio, industria e infraestructura urbana. La diferencia es que, esta vez, los actores sociales responsables de la invasión y destrucción de las áreas arqueológicas ya no son solamente el Estado y las clases acomodadas, sino también los migrantes y sus descendientes, aquel grupo diverso de personas que el antropólogo José Matos Mar (2014) refirió como parte del «desborde popular» y creadores de «La Nueva Lima». $\mathrm{Al}$ igual que en el período colonial, en el que muchos indígenas participaron de manera directa e indirecta del saqueo de huacas y de la búsqueda de tesoros en una costumbre que ha perdurado hasta la actualidad, a pesar de los esfuerzos de arqueólogos y autoridades, aquí también tenemos un discurso e imaginario complicado, en el que parte del proceso de «apropiación» simbólica del paisaje prehispánico de parte de los actores tradicionalmente marginados incluiría la apropiación física, la posibilidad de obtener beneficios y ganancias, a través de la explotación de las huacas y del terreno que ocupan. Actualmente, estos creadores de la «Nueva Lima» presentan una gran diversidad de identidades, discursos y percepciones sobre los sitios arqueológicos, que son complejos y, a veces, aparentemente contradictorios. Estos reflejan sus valores respecto al patrimonio, las prioridades y necesidades de vivir en la ciudad, las percepciones sobre el proceso de ruina y los espacios públicos, y sobre los usos considerados «aceptables» o no para las huacas. Los descendientes del «desborde popular» conforman hoy un grupo heterogéneo que refleja una enorme diversidad de identidades 
y agendas, entre las cuales se incluyen las de los traficantes de terrenos, los activistas, los liderazgos locales y regionales, los profesionales (arqueólogos, historiadores, entre otros), entre otros.

Todos estos sesgos que hemos presentado para buscar entender el porqué de la narrativa limitada de las huacas, y la negación intencional o inconsciente de su larga historia representarían una visión del patrimonio cultural que refleja maneras de pensar, recordar, organizar de grupos de personas, y qué valores se ven en el pasado y en la cultura material (Lowenthal 2002) ¿Qué historias buscamos construir y narrar sobre las huacas?, ¿para qué público?, ¿con qué objetivo?, ¿qué historias buscamos visibilizar?, ¿cuáles preferimos esconder?, ¿por qué establecemos estas diferencias?, ¿de qué manera nos identificamos y cómo identificamos a los demás a través de las narrativas que se crean alrededor de las huacas?

\section{Las huacas y la ciudad multidimensional, o cómo una huaca puede contar muchas historias}

En el presente texto, hemos planteado varias interpretaciones que explican por qué la narrativa de las huacas en Lima se suele limitar al período prehispánico, a partir de lo cual se margina la historia colonial y republicana. En primer lugar, se debe considerar la existencia de un sesgo que asocia arqueología-pasado prehispánico e historia-pasado colonial y republicano, el cual se refleja en la educación, en las instituciones públicas y privadas, y en la legislación. Una consecuencia de esta asociación es que delega la principal responsabilidad de proteger, estudiar, preparar proyectos de «puesta en valor» y construir la narrativa «oficial» de las huacas a los arqueólogos. Esta narrativa «oficial» es la que se ve plasmada en los proyectos de "puesta en valor», y en los materiales educativos y de difusión. La escasez de estudios y enfoques verdaderamente interdisciplinarios también contribuye a esta narrativa limitada. Aunque otros actores y grupos también han construido, y siguen construyendo historias y narrativas sobre las huacas tanto desde perspectivas formales, científicas y académicas (arquitectos, historiadores, urbanistas) como más informales (historias orales y testimonios de vecinos, niños, entre otros), estas diferentes narrativas permanecen inconexas, orientadas a diferentes públicos y no se encuentran integradas a la narrativa «oficial».

La segunda interpretación se basa en una percepción de la historia colonial y republicana como una historia «negativa», que se prefiere marginar y hacer invisible, debido a que se trata de períodos asociados al saqueo, ruina y destrucción de los edificios prehispánicos y su infraestructura. Esta visión negativa de la ruina y el deterioro reflejaría un deseo de valorar las huacas como arquitectura e infraestructura del pasado, y centros de actividad de las sociedades prehispánicas, un mensaje que arqueólogos como Julio C. Tello y Arturo Jiménez Borja utilizaron para cambiar la visión negativa que muchas personas y grupos (hacendados, terratenientes, incluso las municipalidades) tenían de las huacas durante el siglo XX. En una época en la que estas eran percibidas como cerros «sin valor histórico», que podían ser demolidos para proyectos de urbanización o para la obtención de materiales de construcción, los estudios y proyectos de reconstrucción y "puesta en valor» en sitios como Huallamarca, Pucllana y Puruchuco fueron esenciales para que el público - especialmente aquellos individuos y grupos con poder y autoridad para decidir el futuro de las huacas - cambiara su percepción tanto de estos sitios como de las sociedades prehispánicas que los construyeron.

No obstante, pese a que esta estrategia fue esencial para salvar a muchas huacas de la destrucción, también terminó «congelándolas» en un pasado específico, en lo que se consideraba que habría sido la forma «original»o "final». Esta condición es problemática porque los edificios, al igual que las mentalidades, los valores y las formas de pensar y vivir de las sociedades, no son estáticos, sino que se caracterizan por el cambio, por estar en flujo perpetuo. De la misma manera, los materiales tienen un ciclo de vida, y el deterioro e incluso la destrucción son partes naturales e inevitables de este ciclo. Los trabajos de conservación solo pueden retrasar este proceso, mas no detenerlo. El reto consiste en cómo superar los prejuicios y miedos existentes contra el estado de ruina, especialmente, aquel prejuicio que asocia ruina con abandono, desolación y eventual destrucción; cómo presentar el deterioro como una etapa más del ciclo de vida de los edificios; y cómo enfatizar los múltiples significados y memorias, en vez, del estado de «ruina». 
La existencia de esta «historia negativa» y la creación de una narrativa limitada a lo prehispánico estarían relacionadas a cuestiones de identidad, política, y de derecho a la ciudad y a la ciudadanía de un grupo mayoritario y diverso, pero históricamente marginado. Cuando miembros de este grupo tuvieron la oportunidad de construir la narrativa de las huacas mediante proyectos de investigación, conservación, puesta en valor y educación, muchos habrían buscado construir una historia que reforzara los vínculos con las sociedades prehispánicas, y, de esta manera, legitimar el reclamo de ciudadanía y derecho a la ciudad en un contexto de exclusión y discriminación. De la misma manera, lo que se elige convertir un patrimonio mediante canales oficiales, y la manera como otros actores y grupos en una sociedad reaccionan y responden ante esta declaración revela los diferentes valores y mentalidades de una sociedad.

Para ilustrar el impacto de esta narrativa limitada, plantearemos un ejemplo de cómo esta afecta a un grupo social importante: los nińos. En el año 2012, la Municipalidad Metropolitana de Lima organizó un concurso de dibujo para niños llamado «El Patrimonio No Está Pintado», que retaba a los participantes a representar su visión de las huacas de Lima o de su barrio. Una de las participantes presentó un dibujo del pasado y futuro de la huaca Cruz Blanca, en el distrito de San Borja. Lo interesante de este dibujo es que, en las dos vistas, la huaca se ve casi igual, mientras que la ciudad del futuro muestras edificios futuristas y vehículos voladores. El dibujo comunica una idea sencilla: la huaca siempre ha sido prehispánica y solamente prehispánica; siempre ha sido como la vemos ahora; y la huaca es eterna y permanece intacta, aun cuando la ciudad cambie dramáticamente. Se podría asumir que esta visión refleja la narrativa creada alrededor de las huacas, y que es comunicada a la gente que las visita en los materiales educativos y de difusión: una narrativa que "congela» las huacas en un pasado específico, y las presenta como elementos intangibles y eternos. Sin embargo, esta visión desconecta a la huaca del entorno urbano que la rodea, expone una sola historia y percepción del pasado, y presenta a las huacas como eternas y estáticas. En el caso de Lima, las huacas se distinguen especialmente por su longevidad y resistencia, aun considerando el deterioro causado por acción natural y humana. En una ciudad que sufre de sismos regulares, la resistencia y la perduración de las huacas son significativas, especialmente si tenemos en cuenta que muchos de estos sitios han sobrevivido durante cientos e incluso miles de años, la mayoría sin el beneficio de medidas de protección y mantenimiento, mientras que edificios de los períodos colonial, republicano y moderno son destruidos de manera regular. Es irónico que, en Lima, un montículo prehispánico milenario que ha sobrevivido siglos de desastres naturales pueda ser destruido en pocos días con maquinaria pesada. Los sitios arqueológicos de la ciudad son simultáneamente fuertes y frágiles, eternos y efímeros, y se distinguen por el cambio.

En una ciudad multidimensional, la ciudad moderna está sobrepuesta sobre múltiples capas históricas, y sobre el paisaje natural existente. Algunas de estas capas son profusas y densas, y contienen numerosos edificios y espacios, mientras que otras capas son casi traslúcidas, de las cuales solo quedan algunos restos e improntas fragmentadas. La ciudad multidimensional tiene muchos usos, muchas configuraciones, muchos espacios, y es la materialización de las muchas ideas y agendas que la han formado a través del tiempo. El tejido urbano, y la disposición de los espacios construidos y abiertos muestran cómo las diferentes capas interactúan; ninguna de estas es ni debería ser un espacio vacío o negativo. La ciudad multidimensional es también una ciudad dinámica y en movimiento, que constantemente se redefine y reinventa a sí misma. Tanto la ciudad como las huacas son el resultado de una compleja interacción entre fuerzas visibles e invisibles, entre las maneras como los actores sociales interactúan entre sí, negociando, conciliando, ejerciendo, e —incluso - imponiendo su influencia y sus ideas en la ciudad, marcándola, usándola, describiéndola, explotándola y creando sus propias narrativas asociadas a ella. De la misma manera, las huacas y monumentos históricos son territorios contestados, y han sido utilizados como herramientas políticas para construir narrativas históricas, asociadas a la identidad, para la inclusión y la exclusión social, y para la apropiación tanto del territorio físico como de la historia.

En el presente, existe una tendencia hacia una diversidad y pluralidad de interpretaciones del pasado, aunque no todas estas son igualmente válidas, puesto que algunas presentan evidencia 
más sólida y han sido evaluadas de manera más rigurosa que otras. Esta es la razón por la que la construcción de la historia nunca es un proceso terminado y objetivo, y por la que lo que creemos que sabemos es constantemente reexaminado y reevaluado. Estas interpretaciones evolucionan a medida que nuestras ideas y valores sobre lo que constituye valor histórico cambian, a medida que nuevas evidencias se vuelven accesibles, a medida que actores sociales tradicionalmente marginalizados y con poca representación comienzan a investigar y narrar sus propias historias, y a medida que los desarrollos en ciencia y tecnología llevan a nuevas herramientas y teorías que expanden los límites de lo que puede ser conocido (Lowenthal 1985, 1998, 2002; Green 1997; Bluestone 2011).

A partir de ello, podemos concluir que, si entendemos a las huacas como edificios y paisajes históricos y culturales, como conexiones materiales y tangibles con el pasado, y como pequeños palimpsestos, es viable que las huacas puedan contar muchas historias y tener muchos valores, memorias asociadas y significados. Narrar la larga historia de las huacas desde una perspectiva interdisciplinaria que valore la integridad más que la estricta intangibilidad, que visibilice la «historia negativa» y que muestre de manera transparente las múltiples agendas contradictorias de los actores sociales no invalida ni niega estas historias, pero sí reconoce su existencia. La larga historia implica aceptar las huacas como paisajes culturales con un ciclo vida natural e inevitable. Visibilizar la larga historia significa entender las huacas como la materialización de procesos históricos y sociales, de memorias y significados distintos y hasta contradictorios. Finalmente, construir una narrativa que incluya la larga historia es darles la oportunidad a las huacas para que sigan acumulando significados y memorias, además de la responsabilidad de conservar no solo lo que en la actualidad se considera de valor, sino también lo que podría ser significativo para las futuras generaciones.

\section{Notas}

${ }^{1}$ Según Luis Felipe Villacorta, director del proyecto de investigaciones arqueológicas de la huaca Huantinamarca, la historia de la Feria Internacional del Pacífico / Feria del Hogar no ha sido el tema de ningún estudio académico, y prácticamente toda la información disponible proviene de fotografías, testimonios orales y descripciones informales que se encuentran principalmente en fuentes digitales, como blogs y foros de discusión.

${ }^{2}$ En el presente estudio, el término «monumental» es usado para describir aquellos edificios públicos diseñados para poder ser reconocidos, y que pueden ser distinguidos por su gran escala y elaboración, que exceden los requerimientos de cualquier función práctica que el edificio tenía que cumplir. Esta definición de monumentalidad se basa en aquellas propuestas por Moore (1996) y Wason (1994).

${ }^{3}$ Mateo Salado es el nombre oficial del complejo arqueológico actualmente, aunque el sitio también es conocido por otros nombres, como Ascona (nombre de la hacienda en cuyos terrenos se ubicaba el complejo y urbanizada durante el siglo XX) y Cinco Cerritos. La primera mención del sitio la realiza Antonio de la Calancha en su Crónica Moralizada (1638) y el sitio es luego descrito por viajeros del siglo XIX, como Thomas J. Hutchinson (1873) y Ernst W. Middendorf (1884).

${ }^{4}$ Aunque las ruinas prehispánicas suelen ser utilizadas para rituales y ofrendas tales como los llamados "pagos a la tierra», estas ofrendas también pueden ser ubicadas en ruinas más recientes, especialmente iglesias y capillas. En el año 2010, la autora del presente texto realizó un estudio en las ruinas de una iglesia del siglo XVIII en Eten, Lambayeque. Uno de los primeros hallazgos fue un «amarre», que, de acuerdo con la tradición local, es un ritual que una persona realiza con ayuda de un chamán para recuperar a un amante perdido. Este hallazgo sugiere que, incluso en su estado abandonado, hay gente que considera que las ruinas de esta antigua iglesia tienen mucho poder.

${ }^{5}$ Este reglamento, vigente a la fecha de la redacción del presente artículo, fue aprobado por resolución suprema 004-2000-ED y publicado en el Diario Oficial El Peruano el día 24 de enero del año 2000. Una versión nueva del Reglamento fue publicada el día 4 de octubre del 2014. 
${ }^{6}$ Algunos de los tratados internacionales más importantes que guían la arqueología profesional, así como la conservación y tratamiento de sitios arqueológicos e históricos en todo el mundo, son la Carta de Atenas para la Restauración de Monumentos de Arte e Historia (Conferencia Internacional de Atenas, Grecia, 1931), la Carta de Venecia para la Conservación y Restauración de Monumentos y Sitios (II Congreso Internacional de Arquitectos y Técnicos en Monumentos Históricos - CIAM, Venecia, 1964), la Carta de Machu Picchu sobre Ciudades Históricas (Ciam, Cusco, Perú, 1977), la Carta de Washington, Carta Internacional para la Conservación de Poblaciones y Áreas Urbanas Históricas (Concejo Internacional sobre Monumentos y Sitios - Icomos, Washington, 1987), la Carta Internacional para la Gestión del Patrimonio Arqueológico (Icomos, Lausana, Suiza, 1990), la Carta de Burra para Sitios de Significación Cultural (Icomos Australia, 1999), la Carta de Icomos sobre los Principios de Análisis, Conservación y Restauración de las Estructuras del patrimonio Arquitectónico (Icomos Zimbabwe, 2003), y los Principios de Ética Arqueológica de la Sociedad de Arqueólogos Americanos (1996), entre otros. En el Perú, la práctica de la arqueología profesional es regulada por varias instituciones y regulaciones, notablemente la actual Ley General del Patrimonio Cultural de la Nación (ley 28296, aprobada el 21 de julio de 2004); el actual Reglamento de Investigaciones Arqueológicas, aprobado el 24 de enero de 2000; el actual Texto Único de Procedimientos Administrativos, que regula los aspectos administrativos de la profesión; y el Reglamento para la Declaratoria y Gestión de los Paisajes Culturales como Patrimonio Cultural de la Nación (decreto supremo 002-2011-MC).

${ }^{7}$ La narrativa «oficial» sobre las huacas y el pasado prehispánico podría ser considerada aquella presentada en los materiales educativos distribuidos por el Ministerio de Educación a los colegios públicos. El Ministerio también establece guías y estándares sobre el currículo y los temas en todos los cursos, incluida Historia del Perú. Con respecto a aquellos sitios que han sido intervenidos por arqueólogos, la narrativa «oficial» es aquella que guía la investigación, la conservación, la "puesta en valor», y los materiales de educación y difusión que se dan a los visitantes (folletos, paneles, libretos de los guías, entre otros).

${ }^{8}$ Este reglamento fue aprobado mediante decreto supremo 002-200-MC, el día 26 de mayo del año 2011. La principal institución del Estado encargada de estos temas es la Dirección de Paisaje Cultural del Ministerio de Cultura.

${ }^{9}$ La obligación de las Municipalidades y gobiernos locales de proteger los sitios arqueológicos ubicados en su jurisdicción recién fue formalizada en los artículos 82 (numero 12), 91 y 96 (número 3) de la Ley Orgánica de Municipalidades (ley 27972), aprobada el 27 de mayo del año 2003.

${ }^{10} \mathrm{La}$ arquitectura de la huaca Huantinamarca sufrió numerosos cambios a lo largo de su existencia y esta intervención ha sido un episodio más en su dilatada historia. Equipo de Conservación y Restauración del Proyecto Arqueológico Huaca Huantinamarca. San José S.A.C. (Villacorta 2011a: 11).

${ }^{11}<$ https://sites.google.com/site/colectivocolli/>.

12 «Lima Milenaria» (<http://www.limamilenaria.blogspot.com>) comenzó en el año 2010 como un blog a cargo del periodista Javier Lizarzaburu, que luego fue incorporado al diario nacional El Comercio. En el año 2012, la alcaldesa de Lima Susana Villarán asumió esta visión y declaró a Lima «Ciudad Milenaria» (Lizarzaburu 2012).

${ }^{13}<$ http://salvemoslashuacas.pe/>.

${ }^{14}$ Este grupo se creó como respuesta a la destrucción ilegal de una pirámide del complejo El Paraíso, ubicado en el distrito de San Martín de Porres. Su objetivo es promover la revalorización del patrimonio material e inmaterial, así como el uso de la bicicleta como medio de transporte (Círculo Ciclista Protector de las Huacas <http://circulociclistaprotectordelashuacas.blogspot.pe/>). Un dato importante es que muchos de estos grupos de activistas tuvieron su origen en distritos de la «Nueva Lima» como Los Olivos, Comas y la zona de Collique. 


\section{REFERENCIAS}

Avrami, E. C., R. Mason y M. De la Torre

2000 Values and heritage Conservation: Research Report, Getty Conservation Institute, Los Angeles, CA.

Bluestone, D.

2011 Buildings, landscapes and memory: Case studies in historic preservation, W.W. Norton \& Co, New York.

Burger, R. (ed.)

2009 The life and writings of Julio C. Tello: America's first indigenous archaeologist, University of Iowa Press, Iowa.

Calancha, Antonio de la

1638 Crónica moralizada del Orden de San Agustín en el Perú, con svcesos egenplares de esta monarquía. Barcelona: Impr. Pedro Lacavallería.

Cohen, E.

2000 Cultural fusion, en: E. C. Avrami, R. Mason, y M. de la Torre (eds.), Values and Heritage Conservation: Research Report, 44-50, Getty Conservation Institute, Los Angeles, CA.

\section{Concejo Distrital de Miraflores}

1952a Obras de saneamiento en la Huaca Juliana, Revista Municipal de Miraflores 5 (1), julio, 18-20.

1952b Editorial, Revista Municipal de Miraflores 7 (1), setiembre, 11.

1955 Editorial, Revista Municipal de Miraflores 46 (4), setiembre, 22.

Dawdy, S.

2010 Clockpunk anthropology and the ruins of modernity, Current Anthropology 51 (6), 761-793. https://doi. org/10.1086/657626

De las Casas, G. y N. Faustino

2011 Restauro, Huaca Huantinamarca: Arqueología y transformación urbana en la Lima del siglo XXI, 60-99, San José Peru SAC /Arqueoandes, Lima.

Estenssoro Fuchs, J. C.

2003 Del paganismo a la santidad, Instituto Francés de Estudios Andinos, Lima.

Flores, I.

2002 Pucllana: experiencia e historia de una gestión cultural, en: S. Tello (comp.), III Encuentro Iberoamericano Forum Unesco, Universidad y Patrimonio: En torno al patrimonio e interdisciplinareidad, Universidad de San Martín de Porres, Lima.

2005 Pucllana: esplendor de la cultura Lima, Instituto Nacional de Cultura, Lima.

Flores Galindo, Alberto

1988 Buscando un Inca: Identidad y utopía en los Andes, Editorial Horizonte/Instituto de Apoyo Agrario, Lima.

Green, $\mathrm{H}$.

1997 The Social construction of historical significance, en: M. Tomlan (ed.), Preservation of what, for whom? A critical look at historical significance, National Council for Preservation Education, Ithaca.

Herscher, A.

2006 Counter-heritage and violence, Future Anterior 3 (2).

Hutchinson, T.

1873 Two years in Peru, with exploration of its antiquities, Sampson Low, Marston, Low and Searle, London.

Instituto Nacional de Cultura, Perú

2000 Reglamento de Investigaciones Arqueológicas, 24 de enero, Lima.

Lettersten, $\mathrm{M}$.

2014 Diez cartas: La historia de la feria, Aerolíneas Editoriales S.A.C/Sello Editorial Mitin, Lima.

Lizarzaburu, J.

2012 Guerreros de la historia, defensores de identidad, Diario El Comercio, 11 de marzo, Lima.

Lowenthal, D.

1985 The past is a foreign country, Cambridge University Press, Cambridge. 
1998 Fabricating heritage, History and memory 10 (1), 5-24.

2002 The Past as a theme park, en: T. Young y R. Riley (eds.), Theme park landscapes: antecedents and variations, 11-23, Dumbarton Oaks Research Library and Collection, Washington, D.C.

Ludeña, W.

2003 Piqueras urbanista en el Perú o la invención de una tradición, en: L. E. Wuffarden (ed.), Manuel Piqueras Cotoli (1885-1937): Arquitecto, escultor y urbanista entre España y el Perú, Museo de Arte de Lima, Lima.

Lynch, K.

1990 Wasting away, Sierra Club Books, San Francisco.

Mannarelli, M. E.

1985 Inquisición y mujeres: Las hechiceras en el Perú durante el siglo XVII, Revista Andina 3 (1), 141-155.

Matos Mar, J.

2014 Estado desbordado y sociedad nacional emergente: Historia corta del proceso peruano, 1940-2010, Universidad Ricardo Palma, Centro de Investigación, Lima.

McCracken, G.

1988 Culture and consumption: New approaches to the symbolic character of consumer goods and activities, Indiana University Press, Bloomington/Indianapolis.

Meskell, L.

2002 Negative heritage and past mastering in archaeology, Anthropological Quarterly 75 (3), 557-574. https:// doi.org/10.1353/anq.2002.0050

Middendorf, E.

1973 Perú, tomo II, Universidad Nacional Mayor de San Marcos, Lima.

[1887]

Ministerio de Cultura

2011 Reglamento para la declaratoria y gestión de los paisajes culturales como patrimonio cultural de la Nación, 21 de mayo, Lima.

2014 Reglamento de investigaciones arqueológicas, 4 de octubre, Lima.

Moore, J.

1996 Archaeology and power in the ancient Andes: The archaeology of public buildings, Cambridge University Press, New Studies in Archaeology, Cambridge. https://doi.org/10.1017/cbo9780511521201

San José Perú S.A.C

2011 Huaca Huantinamarca: Arqueología y transformación urbana en la Lima del siglo XXI, San José Perú SAC/ Arqueoandes, Lima.

Skar, S. L.

1994 Lives together, worlds apart: Quechua colonization of the jungle and the city, Scandinavian University Press/ Oxford University Press, Oslo/New York.

Tello, J. C.

1999 Cuadernos de Investigación del Archivo Tello No. 1: Arqueología del valle de Lima, Museo de Arqueología y Antropología, Universidad Nacional Mayor de San Marcos, Lima.

Villacorta Ostolaza, L. F.

2004 Puruchuco, medio siglo después, en: L. F. Villacorta Ostolaza (ed.); L. M. Vetter Parodi y C. Ausejo Castillo (cols.), Puruchuco y la sociedad de Lima: Un homenaje a Arturo Jiménez Borja, 69-96, CONCYTEC, Lima.

2011a Huaca, Huaca Huantinamarca: Arqueologia y transformación urbana en la Lima del siglo XXI, 12-25, San José Perú SAC /Arqueoandes, Lima.

2011b Prospectiva, Huaca Huantinamarca: Arqueología y transformación urbana en la Lima del siglo XXI, 156-183, San José Perú SAC/Arqueoandes, Lima.

Villacorta, L. F., M. del Carpio, A. Solís y J. L. Vargas

2011 Huantinamarca, Huaca Huantinamarca: Arqueologia y transformación urbana en la Lima del siglo XXI, 26-59, San José Perú SAC/Arqueoandes, Lima. 
Wason, P.

1994 The archaeology of rank, Cambridge University Press, Cambridge. https://doi.org/10.1017/cbo97805 11521195

Yablon, N.

2009 Untimely ruins: An archaeology of american urban modernity 1819-1919, University of Chicago Press, Chicago. https://doi.org/10.7208/chicago/9780226946658.001.0001

Zevallos Quińones, J.

1994 Huacas y huaqueros en Trujillo, durante el Virreinato (1535-1835), Normas Legales, Trujillo. 